\section{Bahasa Buru di Pesisir Utara Pulau Buru: Sebuah Tinjauan Awal terhadap Daya Hidupnya}

Inayatusshalihah Badan Pengembangan dan Pembinaan Bahasa Surel: inaysha81@gmail.com

\title{
INTISARI
}

Indonesia merupakan negara yang memiliki banyak bahasa daerah. Namun, kepunahan mengancam keberadaan bahasa-bahasa itu terutama di wilayah Indonesia bagian timur seperti Maluku. Ancaman kepunahan dapat disebabkan oleh faktor eksternal dan internal. Kedua faktor itu bersama-sama menghentikan transmisi bahasa dan tradisi kultural antargenerasi. Tulisan ini memaparkan daya hidup bahasa Buru yang dituturkan oleh masyarakat Desa Wamlana, Kecamatan Fena Leisela di pesisir utara Pulau Buru, Maluku dengan menggunakan sembilan faktor vitalitas dan keterancaman UNESCO. Data mengenai daya hidup bahasa Buru dijaring dengan kuesioner. Hasil analisis menunjukkan daya hidup bahasa Buru di Desa Wamlana mengalami ancaman pada beberapa faktor vitalitas. Dari segi rasio penutur dalam total populasi, mayoritas penduduk Desa Wamlana merupakan etnis Buru, tetapi bahasa Buru hanya digunakan oleh generasi orang tua ke atas. Sementara anak-anak tidak mampu menuturkan bahasa Buru secara aktif karena terinterupsinya transmisi bahasa antargenerasi. Penggunaan bahasa Buru mengalami pergeseran ke arah penggunaan bahasa Melayu Ambon. Bahasa Buru hanya digunakan pada ranah dan fungsi yang terbatas. Letak Desa Wamlana di daerah pesisir merupakan salah satu faktor yang memengaruhi daya hidup bahasa Buru. Di wilayah tersebut didapati banyak pendatang dari etnis lain, seperti Buton, Bugis, dan Jawa sehingga kontak bahasa tidak dapat dihindari. Selain itu, ketiadaan regulasi pemerintah berkaitan dengan pelindungan bahasa Buru juga turut menjadi penyebab lemahnya daya hidup bahasa Buru di Desa Wamlana.

Kata kunci: bahasa Buru, daya hidup, faktor vitalitas

\section{PENDAHULUAN}

Bahasa merefleksikan cara pandang dan budaya komunitas tuturnya yang unik, mencerminkan cara mereka dalam menyelesaikan masalah, menyusun pemikiran, filosofi, dan pemahaman tentang dunia di sekitarnya. Dalam hal ini, bahasa merupakan sarana ekspresi warisan budaya tak benda komunitas tuturnya. Bahasa akan tetap menjadi cerminan dari budaya ini bahkan setelah budaya yang mendasarinya meluruh dan runtuh. Namun, dengan kematian dan hilangnya bahasa, unit yang tak tergantikan dalam pengetahuan dan pemahaman kita tentang pemikiran manusia dan pandangan dunia hilang selamanya (Wurm, 2001:13). Karena itu, kematian atau kepunahan sebuah bahasa dapat dikatakan sebagai kepunahan budaya yang tercermin dalam bahasa itu.

Kepunahan bahasa dapat disebabkan oleh faktor eksternal dan internal. Kedua faktor itu bersama-sama menghentikan transmisi bahasa dan tradisi kultural antargenerasi. Sallabank 
(2010) menyebutkan beberapa faktor penyebab kepunahan bahasa, yaitu bencana alam, perang dan genosida, desakan otoritas, dominasi budaya/politik/ekonomi. Keempat faktor tersebut dapat dijabarkan lebih lanjut dalam beberapa faktor yang turut mengakibatkan kepunahan bahasa, yaitu faktor ekonomi (migrasi), dominasi budaya oleh masyarakat mayoritas, politik (kebijakan pendidikan bahasa), sejarah (kolonisasi, konflik daerah perbatasan), dan sikap bahasa.

Dalam konteks Indonesia ancaman kepunahan dialami terutama oleh bahasa-bahasa daerah yang berada di wilayah Indonesia bagian timur seperti Maluku. Kantor Bahasa Provinsi Maluku mencatat dari 48 bahasa daerah di provinsi tersebut, 7 di antaranya sudah punah (seperti Kayeli, Palumata, Moksela, Hukumina, Piru, Loun) dan 22 bahasa terancam punah. Faktor yang menyebabkan ancaman kepunahan terhadap bahasa-bahasa itu di antaranya adalah kuatnya penggunaan bahasa Melayu Ambon dan sikap generasi muda terhadap bahasa daerahnya.

Salah satu bahasa daerah yang dikenal di Maluku adalah bahasa Buru. Bahasa ini termasuk tiga bahasa besar yang dituturkan oleh masyarakat Pulau Buru, Maluku. Meskipun demikian, di beberapa wilayah tuturnya bahasa Buru mengalami penurunan daya hidup yang diakibatkan penurunan jumlah ranah penuturan. Palupi (2017:44), dalam kajiannya mengenai vitalitas bahasa Buru, menyebutkan bahasa Buru yang dituturkan di Desa Fogi, Kecamatan Kepala Madan, Kabupaten Buru Selatan berada pada tahap terancam punah karena penutur sudah tidak lagi menggunakannya dalam aktivitas komunikasi sehari-hari. Bahasa Buru di Desa Fogi telah mengalami pergeseran ke bahasa Melayu Ambon.

Kajian mengenai daya hidup bahasa Buru di seluruh wilayah persebarannya perlu dilakukan untuk memetakan tingkat daya hidupnya di tiap wilayah tutur itu. Gambaran yang komprehensif mengenai daya hidup bahasa Buru di Pulau Buru akan memudahkan pemangku kepentingan dalam membuat kebijakan yang tepat terkait pelindungan dan pelestarian bahasa daerah. Oleh karena itu, tulisan ini bertujuan melihat daya hidup Bahasa Buru dialek Lisela yang dituturkan di Desa Wamlana, Kecamatan Fena Leisela, Kabupaten Buru berdasarkan sembilan faktor vitalitas dan keterancaman bahasa yang ditetapkan UNESCO.

Daya hidup berkenaan dengan kemampuan sebuah bahasa untuk bertahan hidup dan berkembang. Sebuah bahasa dapat dikatakan memiliki daya hidup yang baik apabila bahasa itu digunakan sebagai alat komunikasi di dalam berbagai konteks sosial. Daya hidup suatu bahasa dapat diukur berdasarkan tiga faktor dasar, yaitu demografi, status, dan dukungan institusional. Ketiga faktor tersebut mempunyai kontribusi yang sangat penting terhadap daya hidup suatu bahasa sehingga dinyatakan semakin tinggi status, banyak dukungan institusional, dan 
demografi yang menguntungkan, maka semakin tinggi daya hidup yang dimiliki oleh sebuah kelompok etnolinguistik (Joan, 2015:5).

Ada sejumlah faktor yang terlibat dalam penentuan tingkat daya hidup bahasa. Faktor itu ada yang terkait erat dengan pergeseran bahasa, sifat penutur, ranah penggunaan, dan dukungan internal maupun tekanan terhadap penggunaan bahasa (Grenoble, 2011:38). UNESCO (Brenzinger et.al., 2003:9-16) menetapkan 9 faktor penentuan tingkat daya hidup, yakni 6 faktor untuk menilai vitalitas dan tingkat keterancaman, 2 faktor untuk menentukan sikap bahasa, dan 1 faktor untuk menilai pentingnya kebutuhan dokumentasi. Sembilan faktor itu antara lain (1) transmisi bahasa antargenerasi, (2) jumlah penutur, (3) proporsi penutur dalam populasi total, (4) ranah penggunaan bahasa, (5) respon terhadap ranah dan media baru, (6) bahan ajar bahasa dan literasi, (7) sikap dan kebijakan pemerintah dan lembaga kebahasaan, (8) sikap bahasa anggota masyarakat, dan (9) jenis dan kualitas dokumentasi. Masing-masing faktor itu memiliki enam (0-5) skala keterancaman.

Dari sembilan faktor tersebut, transmisi bahasa antargenerasi merupakan faktor terpenting sehingga UNESCO menetapkan tingkat vitalitas dan keterancaman berdasarkan faktor itu (lihat tabel 1). Meskipun sebuah bahasa berada pada tingkat aman, ketahanan hidupnya tidak dapat dijamin karena penutur bahasa itu suatu waktu dapat saja berhenti menurunkan bahasanya kepada generasi selanjutnya. Oleh karena itu, pewarisan bahasa dari satu generasi ke generasi yang lain menjadi faktor utama dalam pengukuran daya hidup sebuah bahasa.

Tabel 1. Tingkat Keterancaman Menurut UNESCO

\begin{tabular}{|c|c|}
\hline Safe & $\begin{array}{l}\text { language is spoken by all generations; intergenerational } \\
\text { transmission is uninterrupted }\end{array}$ \\
\hline Vulnerable & $\begin{array}{l}\text { most children speak the language but it may be restricted to } \\
\text { certain domains (e.g home) }\end{array}$ \\
\hline Definitely endangered & $\begin{array}{l}\text { children no longer learn the language as mother tongue in the } \\
\text { home }\end{array}$ \\
\hline Severely endangered & $\begin{array}{l}\text { language is spoken by grandparents and older generations; } \\
\text { while the parent generation may understand it, they do not } \\
\text { speak it to children or among themselves }\end{array}$ \\
\hline Critically endangered & $\begin{array}{l}\text { the youngest speakers are grandparents and older, and they } \\
\text { speak the language partially and infrequently }\end{array}$ \\
\hline Extict & the are no speakers left \\
\hline
\end{tabular}

Adapun data kajian ini dikumpulkan dengan menggunakan kuesioner sebagai instrumen dan dilengkapi dengan wawancara informal. Kuesioner disusun berdasarkan kerangka kriteria vitalitas bahasa UNESCO (Brenzinger et.al. 2003). Kuesioner diberikan kepada 50 responden yang terdiri dari laki-laki dan perempuan dengan tiga kelompok usia, yakni >25 tahun, 25-50 tahun, dan $>50$ tahun. Data primer yang dijaring dengan kuesioner ditabulasi menggunakan 
program Microsoft Excel dan diolah menggunakan Statistical Package for Social Sciences (SPSS) untuk melihat frekuensi dan persentase jawaban responden terhadap setiap butir pertanyaan yang merupakan indikator pengujian vitalitas bahasa. Nilai rata-rata (mean) dari keluaran SPSS tersebut kemudian dianalisis menggunakan sembilan indikator vitalitas bahasa UNESCO. Semakin banyak dari sembilan faktor itu berada pada kategori aman, maka daya hidup bahasa berada pada daya hidup yang baik. Sebaliknya, jika sedikit dari sembilan faktor tersebut yang berfungsi dengan baik, maka daya hidup bahasa semakin rendah. Penetapan tingkat daya hidup menggunakan enam tingkat vitalitas dan keterancaman UNESCO. Sementara data dari wawancara informal digunakan untuk melengkapi hasil analisis data primer.

\section{HASIL DAN PEMBAHASAN}

\section{Situasi Kebahasaan di Pulau Buru}

Bahasa-bahasa di Pulau Buru dikelompokkan oleh Collins (1983) ke dalam Proto Maluku Tengah. Proto Maluku Tengah terbagi menjadi dua bagian besar, yaitu bagian barat dan bagian timur. Pada bagian barat termasuk bahasa-bahasa yang digunakan penduduk di Pulau Buru dan Pulau Ambalau, sedangkan bagian timur adalah bahasa-bahasa yang digunakan di Pulau Seram, Ambon, Haruku, Saparua, dan Nusalaut (Latupapua, 2015:4). Ada tiga bahasa utama yang dituturkan di Pulau Buru, yakni bahasa Hukumina, Kayeli, dan Buru. Ketiga bahasa itu cukup berbeda sehingga dianggap bahasa yang tersendiri daripada dialek dari satu bahasa (Grimes, 2010:78). Dari ketiga bahasa tersebut, hanya bahasa Buru yang bertahan hidup sampai saat ini. Bahasa Kayeli dan Hukumina dinyatakan telah punah.

Bahasa Buru memiliki lima dialek, yaitu Masarete, Wae Sama, Rana, Lisela, dan Fogi. Di antara lima dialek tersebut, Masarete, Rana, dan Wae Sama masih tetap digunakan sebagai alat komunikasi sehari-hari, sedangkan Fogi dan Lisela mendekati pergerseran ke bahasa Melayu Ambon. Dialek Fogi dan Lisela tidak digunakan untuk interaksi verbal dengan generasi yang lebih muda sehingga dua dialek ini dianggap hampir punah (Grimes, 2010:75).

Tabel 2. Bahasa di Pulau Buru

\begin{tabular}{|c|c|c|c|}
\hline No. & Bahasa & Dialek & Subdialek \\
\hline \multirow[t]{10}{*}{1.} & \multirow[t]{10}{*}{ Buru } & Masarete & - \\
\hline & & Wae Sama & - \\
\hline & & \multirow[t]{4}{*}{ Rana } & Rana \\
\hline & & & Wae Geren \\
\hline & & & Wae Kabo \\
\hline & & & Wae Tina \\
\hline & & \multirow[t]{4}{*}{ Lisela (Li Enyerot) } & Lisela \\
\hline & & & Tagalisa \\
\hline & & & Wae Geren \\
\hline & & & Leliali \\
\hline
\end{tabular}




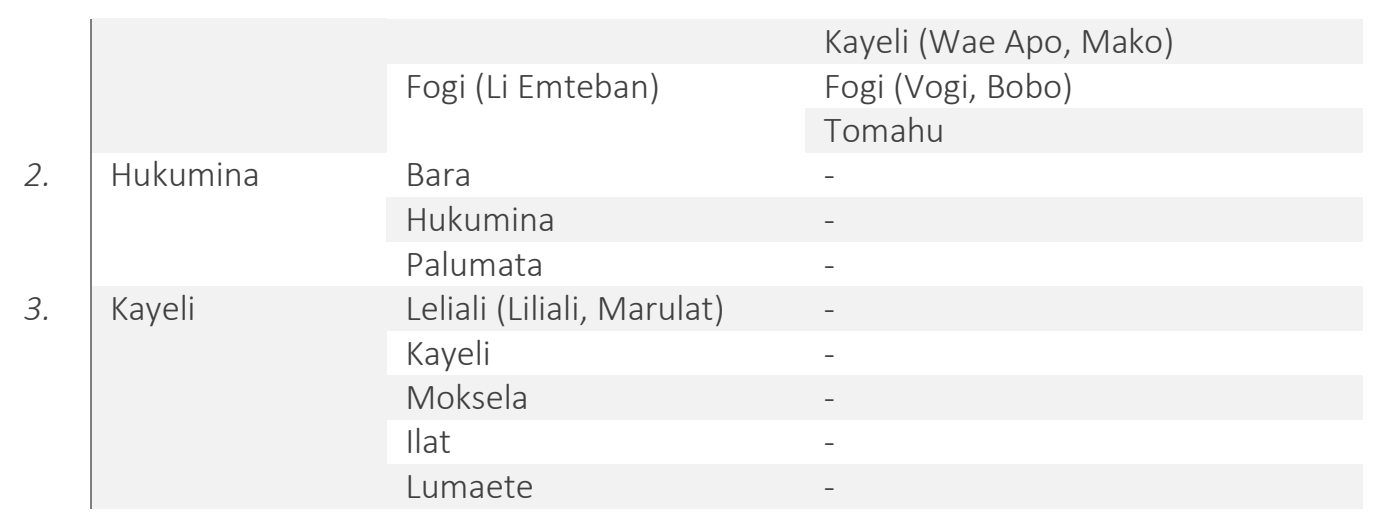

Diadaptasi dari Grimes, 2010:76

Bahasa Buru dalam kajian ini dituturkan oleh penduduk di Desa Wamlana. Bahasa Buru di desa itu dapat dikatakan sebagai bahasa Buru dialek Lisela. Dialek Lisela merupakan salah satu dialek bahasa Buru yang dituturkan di bagian utara pulau Buru di samping bahasa Sula. Menurut Grimes (2010:75), sekitar 12.500 penutur Sula mendiami pantai utara Buru sejak beberapa generasi. Mereka mempertahankan bahasanya dan ikatan dengan tanah asalnya di pulau-pulau utara.

Desa Wamlana terletak di pesisir utara Pulau Buru dan merupakan pusat pemerintahan adat petuanan (regentschaf) Lisela. Desa ini berjarak sekitar $85 \mathrm{~km}$ dari Namlea, ibu kota Kabupaten Buru. Secara administratif, Wamlana masuk dalam wilayah Kecamatan Fena Leisela, Kabupaten Buru. Letak desa Wamlana di wilayah pesisir dan posisinya sebagai pusat pemerintahan tentu mempengaruhi daya hidup bahasa Buru yang digunakan oleh masyarakat yang tinggal di sana.

\section{Daya Hidup Bahasa Buru}

Sebagaimana disebutkan sebelumnya bahwa pengukuran daya hidup bahasa Buru di Desa Wamlana didasarkan pada sembilan faktor vitalitas dan keterancaman yang ditetapkan UNESCO. Hasil pengolahan data menunjukkan daya hidup bahasa Buru yang rendah dan lemah pada sebagian besar faktor vitalitas. Berikut deskripsi daya hidup bahasa Buru di Wamlana pada tiap faktor vitalitas dan keterancaman.

\section{a. Transmisi Bahasa antargenerasi}

Bahasa yang tetap ditransmisikan atau diwariskan antargenerasi akan memiliki daya hidup yang tinggi. Di Wamlana, bahasa Buru digunakan sebagian besar oleh generasi orang tua ke atas. Kelompok usia <20 tahun tidak menguasai lagi bahasa Buru karena bahasa pertama yang diajarkan oleh orang tua adalah bahasa Indonesia atau Melayu Ambon. Menurut responden, bahasa Indonesia diajarkan pertama kali untuk memudahkan anak-anak dalam mengikuti proses belajar mengajar di sekolah karena bahasa resmi di ranah pendidikan adalah bahasa Indonesia. Meskipun berbahasa pertama Indonesia, anak-anak dapat memahami ketika orang tua berbicara dengan mereka menggunakan bahasa Buru, tetapi 
mereka tidak mampu merespon kembali dengan bahasa Buru. Terinterupsinya transmisi bahasa Buru disebabkan juga fenomena perkawinan campur antaretnis di Wamlana. Dalam keluarga kawin campur, bahasa yang dipilih sebagai media komunikasi sehari-hari adalah bahasa Melayu Ambon atau bahasa Indonesia sehingga bahasa itulah yang pertama kali diajarkan, bukan bahasa Buru.

\section{b. Jumlah Penutur dan Proporsi Penutur dalam Populasi Total}

Jumlah penutur dalam hubungannya dengan populasi total suatu kelompok merupakan indikator penting daya hidup sebuah bahasa. Ethnologue menyebutkan bahasa Buru dituturkan oleh 45.000 orang di Pulau Buru (Simons dan Fennig, 2018). Adapun di Desa Wamlana, menurut pengakuan responden, etnis Buru merupakan mayoritas penduduk. Adapun etnis lain yang tinggal di Wamlana merupakan pendatang seperti Buton, Bugis, dan Jawa yang jumlahnya tidak sebanyak etnis tempatan. Dengan demikian proporsi penutur bahasa Buru lebih besar dibandingkan dengan penutur bahasa lain di Wamlana. Meskipun menjadi mayoritas penduduk, etnis Buru yang merupakan penutur aktif dan fasih bahasa Buru hanya generasi orang tua. Tidak semua etnis Buru berkomunikasi sehari-hari menggunakan bahasa Buru.

\section{c. Ranah Penggunaan}

Dalam sosiolinguistik, istilah ranah mengacu pada "...a group of institutionalized social situations typically constrained by a common set of behavioural rules..." (Crystal, 1997:124). Sehubungan dengan ranah, daya hidup sebuah bahasa dapat dilihat dari fungsi dan intensitas penggunaannya pada tiap ranah oleh para penuturnya. Semakin berfungsi dan tinggi intensitas penggunaan bahasa pada berbagai ranah, semakin kuat daya hidup bahasa tersebut (Latupapua, 2015:7). Ranah penggunaan bahasa dalam kajian ini meliputi ranah formal, rumah tangga, agama, pendidikan, dan perdagangan. Dalam ranah formal seperti di kantor pemerintahan dan pusat pelayanan kesehatan, bahasa Buru cenderung tidak digunakan. Demikian pula halnya dalam ranah pendidikan dan agama. Interaksi antara guru dan murid di sekolah, baik di dalam kelas maupun di luar, cenderung menggunakan bahasa Indonesia atau Melayu Ambon. Sementara itu dalam ibadah keagamaan di mesjid cenderung tidak menggunakan bahasa Buru. Menurut pengakuan sebagian responden, mereka akan menggunakan bahasa Buru pada saat berdoa sendiri.

Adapun dalam ranah rumah tangga, bahasa Buru cenderung digunakan. Akan tetapi menurut pengakuan responden, bahasa Buru digunakan di rumah ketika berkomunikasi dengan orang yang lebih tua seperti ayah ibu, kakek nenek, sedangkan dengan anak-anak cenderung digunakan bahasa Indonesia. Dengan demikian dalam ranah rumah tangga digunakan dua bahasa, bahasa Buru dan bahasa Indonesia dengan intensitas yang berbeda. Bahasa Buru 
juga cenderung tidak digunakan dalam transaksi jual beli di pasar. Mereka menggunakan bahasa Buru jika pedagang pasar juga merupakan penutur Buru yang tinggal di luar Wamlana.

Kecenderungan penggunaan bahasa Indonesia atau Melayu Ambon di ranah-ranah publik disebabkan situasi masyarakat Wamlana yang terdiri dari beberapa etnis, yakni Buru, Buton, Bugis, dan Jawa. Bahasa Indonesia sebagai bahasa nasional dipilih sebagai alat komunikasi antaretnis. Meskipun demikian, dapat dilihat bahwa di ranah yang bersifat pribadi, masyarakat Buru Wamlana masih tetap mempertahankan penggunaan bahasa Buru.

\section{d. Respon terhadap Ranah dan Media Baru}

Ranah baru penggunaan bahasa dapat muncul seiring perubahan kondisi kehidupan masyarakat. Sebuah bahasa yang tidak dapat digunakan oleh komunitas tuturnya untuk memenuhi tantangan modernitas dapat dikatakan tidak relevan dengan perkembangan zaman. Hal ini ditemukan dalam bahasa Buru. Menurut pengakuan responden, tidak banyak kosakata baru yang sesuai dengan tantangan zaman dalam bahasa ini. Selain itu, bahasa Buru tidak digunakan dalam ranah baru seperti internet dan media penyiaran (televisi dan radio). Dengan demikian bahasa Buru di Wamlana tidak memenuhi faktor 5 dari kriteria vitalitas UNESCO, yakni bahasa Buru tidak digunakan dalam ranah dan media baru apa pun.

\section{e. Bahan Ajar Bahasa dan Literasi}

Bahasa Buru tidak memenuhi faktor 6 dari kriteria vitalitas UNESCO. Berkenaan dengan faktor itu, bahasa Buru tidak memiliki materi untuk pengajaran dan literasi. Sebagaimana bahasa-bahasa di Maluku yang merupakan bahasa tanpa tulisan atau aksara, bahasa Buru juga merupakan bahasa tanpa tulisan. Tradisi tulis bahasa Buru tidak ditemukan karena ketiadaan ortografi atau sistem tulisan dalam komunitas tutur Buru di Wamlana.

\section{f. Sikap Bahasa Penutur}

Sikap bahasa didefinisikan sebagai perasaan yang dimiliki oleh penutur terhadap bahasanya sendiri. Sikap memegang peran penting dalam penentuan daya hidup bahasa. Semakin loyal penutur terhadap penggunaan bahasanya, semakin kuat daya hidup bahasa itu (Maricar, 2016:1756). Kebanggaan dan loyalitas bahasa menunjukkan sikap positif penutur terhadap bahasanya. Jika penutur tidak memiliki kedua karakteristik itu, maka penutur dikategorikan bersikap negatif terhadap bahasanya. Berkenaan dengan sikap penutur Buru, sebagian besar responden menyatakan bangga atas bahasanya dan menganggap bahasa Buru lebih penting daripada bahasa daerah lain. Responden juga menyatakan bahwa setiap anggota kelompok etnis Buru harus menguasai bahasa Buru. 


\section{g. Sikap dan Kebijakan Pemerintah}

Kebijakan bahasa merupakan peraturan yang berhubungan dengan konstruksi dan implementasi penggunaan bahasa di komunitas tutur tertentu. Sikap dan kebijakan pemerintah terhadap penggunaan bahasa Buru cenderung positif. Akan tetapi, sikap tersebut tidak diikuti kebijakan yang mengatur pelindungan dan pengembangan bahasa Buru. Menurut responden, tidak ada peraturan daerah yang berkenaan dengan pelestarian bahasa Buru, baik berupa kewajiban penggunaan bahasa Buru maupun sanksi bagi pelanggaran penggunaannya; tidak ada kebijakan eksplisit untuk bahasa daerah. Bahasa dominan (bahasa Indonesia) digunakan dalam ranah publik, sedangkan bahasa Buru pada ranah pribadi.

\section{h. Jenis dan Kualitas Dokumentasi}

Dokumentasi bahasa Buru dapat dikatakan dokumentasi yang tidak memadai (inadequate documentation). Berdasarkan penelusuran pustaka, penulis tidak menemukan dokumentasi berupa buku tata bahasa, kamus, literature, atau rekaman audio dan visual bahasa Buru yang lengkap dan komprehensif. Penulis menemukan daftar kata (wordlist) bahasa Buru dan beberapa tulisan hasil penelitian yang berkenaan dengan bahasa Buru, seperti Grimes (1991) The Buru Language of Eastern Indonesia; Grimes (1995) "Buru (Masarete)" dalam Comparative Austronesian Dictionary; dan Sumarlan dkk. (2017) Reflexes of Proto-Austronesia into Buru Language.

\section{KESIMPULAN}

Bahasa Buru di Desa Wamlana memiliki daya hidup yang rendah dalam sebagian besar faktor vitalitas dan keterancaman yang ditetapkan UNESCO. Posisi Wamlana di pesisir menyebabkan penduduk daerah ini menjadi masyarakat multikultural yang tidak hanya didiami oleh etnis Buru, tetapi juga etnis pendatang seperti Buton, Bugis, dan Jawa. Kontak bahasa antaretnis tersebut mendorong penggunaan bahasa Indonesia atau Melayu Ambon sebagai bahasa komunikasi sehingga transmisi bahasa Buru antargenerasi terinterupsi. Anak-anak tidak menguasai lagi bahasa Buru karena bahasa pertama yang mereka kuasai adalah bahasa Indonesia atau Melayu Ambon. Dengan demikian, Bahasa Buru di Wamlana dapat dikatakan berada pada tingkat ke-3 dari skala keterancaman UNESCO, yaitu definitely endangered. Ancaman kepunahan ini diperkuat dengan ketiadaan ortografi dan dokumentasi yang memadai serta ketiadaan kebijakan pemerintah terkait pelestarian bahasa Buru. 


\section{DAFTAR RUJUKAN}

Brenzinger, Matthias et.al. 2003. Language Vitality and Endangerment. (http://www.unesco.org/new/en/culture/themes/endangered-language/ languagevitality/\#unesdoc.unesco.org/images/0018/001836/183699E.pdf, diakses Juli 2015).

Crystal, David. 1997. A Dictionary of Linguistics and Phonetics. Oxford: Blackwell Publishers Inc.

Grenoble, Lenore A. 2011. "Assessing Language Endangerment". Dalam Peter K. Austin dan Julia Sallabank (ed.). The Cambridge Handbook of Endangered Language. Cambridge: Cambridge University Press.

Grimes, Charles E. 2010. "Digging for the Roots of Language Death in Eastern Indonesia: The Cases of Kayeli and Hukumina". Dalam Margaret Florey (ed.). Endangered Languages of Austronesia. Oxford: Oxford University Press.

Joan, Amee. 2015. The Present and Future Vitality of the Kejaman Language in Sarawak. (http://ir.unimas.my/id/edprint/8011, diakses 11 Desember 2015).

Latupapua, Falantino Eryk. 2015. Kebocoran Diglosia dan Pemertahanan Bahasa Tana sebagai Bahasa Adat di Kabupaten Maluku Tengah. (https://caridokumen.com/ download/kebocoran-diglosia-dan-pemertahanan-bahasa-tana-sebagai-bahasa-adatdi-kabupaten-maluku-tengah-_5a46d7ffb7d 7bc7b7a22a6e5_pdf).

Maricar, Farida. 2016. "The Influence Factors of Ternate Language Shift in Ternate City". International Journal of Science and Research. Volume 5:1.

Palupi, Dian. 2017. "Potret Bahasa Buru pada Suku Buru di Pulau Buru: Studi Kasus pada Masyarakat Fogi" dalam Prosiding Seminar Nasional Bahasa dan Sastra: Maertabatkan Bahasa dan Sastra, Rayakan Kebinekaan. Cetakan I. Ambon: Kantor Bahasa Maluku.

Sallabank, Julia. 2010. "Language Endangerment: Problems and Solutions" dalam eSharp, Special Issue: Communicating Change (2010): hlm. 50-87.

Simons, Gary F. dan Charles D. Fennig. 2018. Ethnologue: Languages of the World. Edisi XX. Dallas: SIL International. Online version http://www.ethnologue.com.

Tujuh Bahasa Daerah di Maluku Punah (https://www.antaranews. com/berita/685768/tujuhbahasa-daerah-di-maluku-punah, diakses Maret 2018 ).

Wurm, Stephen A. 2001. Atlas Of the World's Languages in Danger of Disappearing. Paris: UNESCO Publishing. 